\title{
Unindo pesquisa e extensão para fortalecer a participação feminina em cursos de Computação de uma universidade: Projeto Meninas Digitais do Vale
}

\author{
Anna Beatriz Marques, Valéria M. Pinheiro, Ana Iza Alencar, Karina Castelo \\ Branco, Rhenara Alves, Maria Elanne Mendes
}

Universidade Federal do Ceará (UFC) - Campus Russas

CEP 62900-000 - Russas - CE - Brasil

beatriz.marques@ufc.br, \{valeriam.soft, anaizaalencar, karinascb,

rhenaraalves21, elannemendes\}@alu.ufc.br

Abstract. The reinforce of women participation in IT has been a growing concern in universities and companies. Due to the variety of actions that can be carried out with this objective, people interested in starting projects in this area may face difficulties in selecting suitable actions to the context in which they are part of. The aim of this paper is to report the experience in a joint research and extension project for directing the systematic adoption of actions for women participation in Software Engineering and Computer Science courses in an university. The adopted methodology involved the conduction of a systematic mapping, a survey and brainstorming for selecting appropriate actions for the campus and the students' challenges and needs of students.

Resumo. O fortalecimento da participação feminina na área de TI vem sendo uma preocupação cada vez maior em universidades e empresas. Devido à variedade de ações que podem ser executadas com este objetivo, pessoas interessadas em iniciar projetos nesta temática podem enfrentar dificuldades para selecionar ações adequadas ao contexto no qual estão inseridas. $O$ objetivo deste artigo é relatar a experiência do projeto Meninas Digitais do Vale que uniu pesquisa e extensão para selecionar sistematicamente ações para fortalecer a participação feminina nos cursos de Engenharia de Software e Ciência da Computação em uma universidade. A metodologia adotada envolveu a condução de um mapeamento sistemático, um survey e brainstorming para a seleção de ações adequadas ao campus e aos desafios e necessidades das alunas ativas nos cursos.

\section{Introdução}

A redução do número de mulheres em Tecnologia da Informação (TI) tem sido uma preocupação mundial (Maciel e Bim, 2016). De acordo com o último relatório sobre Educação Superior em Computação divulgado pela Sociedade Brasileira de Computação (SBC), observa-se que em 2017, 19.803 mulheres matricularam-se em cursos de Computação, o que representa $13,8 \%$ do total de matriculados (as). Deste número de mulheres ingressantes no curso, somente $31,2 \%$ concluem o curso.

Ações de incentivo para a inserção das mulheres na Computação vêm sendo adotadas por diversas universidades, empresas e instituições de fomento (Cesário et al. 2017). Diferentes ações podem ser adotadas de acordo com os problemas e respectivas causas identificadas em um determinado contexto, sendo necessária a seleção adequada 
de ações. Pessoas interessadas em iniciar projetos de incentivo à participação de mulheres na Computação podem ter dificuldades para selecionar ações adequadas de acordo com a problemática identificada em seu contexto.

Este artigo apresenta um relato de experiência em um projeto de pesquisa e extensão iniciado em 2018, no qual foi definida uma metodologia para selecionar sistematicamente ações adequadas para fortalecer a participação feminina em cursos de Ciência da Computação e Engenharia de Software de um campus do interior de uma universidade federal. Métodos de pesquisa foram adotados para: (1) criar uma base de conhecimento sobre ações publicadas nos anais do Women in Information Technology (WIT); (2) elicitar os desafios e interesses das alunas do campus no qual o projeto é realizado; (3) mapear os desafios e interesses às ações adequadas para promover um maior engajamentos das alunas em seus cursos.

O projeto envolve pesquisa ao adotar metodologias de Engenharia de Software e Interação Humano-Computador (IHC) para caracterizar ações existentes e delinear o perfil das alunas do campus. A extensão se deu por meio da realização de ações direcionadas aos estudantes do campus e à comunidade, com foco em estudantes do ensino médio. Espera-se que este relato de experiência possa contribuir no planejamento de projetos com temática similar, além de divulgar os resultados obtidos neste projeto.

O restante deste artigo está organizado da seguinte maneira: a Seção 2 apresenta a metodologia adotada no projeto. A Seção 3 apresenta um resumo das ações realizadas ao longo de 2018 e os principais resultados obtidos. Por fim, são apresentadas as considerações finais e perspectivas futuras desta pesquisa.

\section{Metodologia do projeto de pesquisa e extensão}

O projeto Meninas Digitais do Vale iniciou em abril de 2018 em um campus da Universidade Federal do Ceará (UFC) localizado na cidade de Russas no interior do estado Ceará. Todos os cursos ofertados no campus são da área de Exatas. Na área de TI, são ofertados os cursos de Ciência da Computação e Engenharia de Software. Em uma análise conduzida pelas coordenações de tais cursos em 2018, observou-se que somente $20 \%$ das vagas ofertadas eram preenchidas por mulheres. Além disso, a média de evasão de mulheres no curso de Engenharia de Software era de $40 \%$ enquanto no curso de Ciência da Computação era de $70 \%$.

O projeto foi uma iniciativa de uma professora do campus do curso de Engenharia de Software que, diante do cenário apresentado, criou o projeto com o intuito de fortalecer a participação das alunas nos cursos de Ciência da Computação e Engenharia de Software, e consequentemente aumentar o índice de ingresso e permanência de alunas no campus. A equipe inicial do projeto era composta pela professora coordenadora e seis alunas voluntárias, sendo cinco alunas do curso de Engenharia de Software e uma aluna do curso de Ciência da Computação.

Como a equipe não possuía experiência prévia em outros projetos direcionados ao engajamento de mulheres na área de TI, três questões principais surgiram durante o planejamento do projeto, tais como: O que justifica o índice atual de evasão de alunas nos cursos de Ciência da Computação e Engenharia de Software do campus? Quais ações existentes para o fortalecimento da participação de mulheres na área de TI? Quais as ações adequadas para minimizar os problemas enfrentados pelas alunas do campus?

Para responder às questões, decidiu-se adotar a metodologia descrita na Figura 1. 


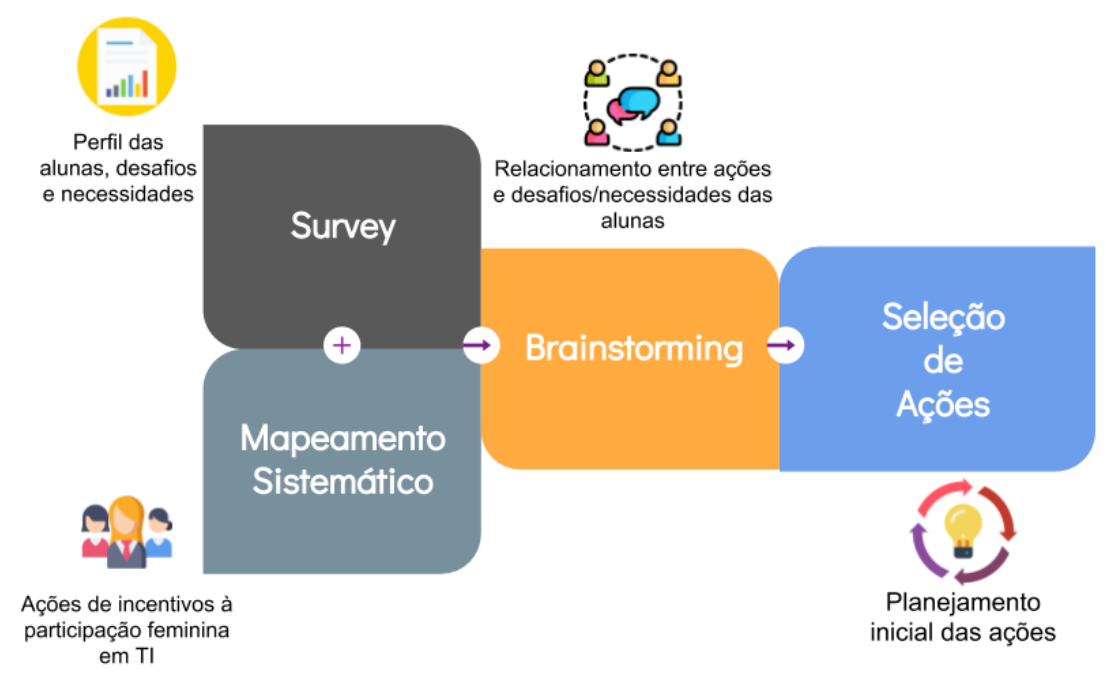

Figura 1. Metodologia adotada no projeto de pesquisa e extensão.

Mapeamento sistemático: um mapeamento sistemático é um tipo de revisão sistemática que possui questões de pesquisa exploratórias (Kitchenham e Chartes, 2010). O objetivo desta etapa consistiu em identificar quais as ações existentes para o fortalecimento de mulheres no âmbito do programa Meninas Digitais. Duas alunas do projeto conduziram o mapeamento sob a supervisão da coordenadora do projeto.

Survey: uma pesquisa survey consiste na obtenção de informações sobre características, ações ou opiniões de determinado grupo de pessoas, por meio de um instrumento de pesquisa, normalmente um questionário (Wohlin et al., 2012). O intuito da condução do survey foi delinear o perfil das alunas de Engenharia de Software e Ciência da Computação do campus, os desafios enfrentados que podem ocasionar a evasão e suas necessidades em relação ao desenvolvimento da carreira acadêmica e profissional. O survey foi conduzido por três alunas do projeto em paralelo ao mapeamento sistemático.

Brainstorming: com os resultados do mapeamento sistemático e do survey, um brainstorming foi conduzido para incentivar a discussão e sugestão de relações entre as ações identificadas no mapeamento sistemático e os problemas e necessidades apontados pelas alunas no survey. Toda a equipe participou do brainstorming.

Seleção de ações: a equipe realizou um levantamento de eventos promovidos pelo campus, nos quais algumas ações poderiam ser realizadas, bem como datas estratégicas para execução de ações independentes. Nesta etapa, também foram considerados os recursos necessários para a execução das ações, uma vez que o projeto ainda não possui apoio financeiro.

Nas próximas subseções, serão descritas as três primeiras etapas da metodologia do projeto. Na Seção 3, serão apresentadas as ações realizadas no primeiro ano do projeto.

\subsection{Mapeamento Sistemático de ações relatadas no Women in Information Technology}

Um mapeamento sistemático foi conduzido para analisar publicações científicas do evento WIT (2016 e 2017) com o propósito de identificar e caracterizar ações realizadas 
para promover a participação de mulheres na área de TI no âmbito do Programa Meninas Digitais. O mapeamento foi conduzido entre abril e junho de 2018. A questão de pesquisa principal do mapeamento sistemático foi "Quais ações foram executadas no Brasil para a promoção da participação de mulheres na área de TI?". Como questões de pesquisa secundárias, é possível definir: (i) "Qual o público alvo e ambiente no qual a ação foi realizada?"; (ii) "Qual o objetivo específico da ação no contexto da promoção da participação de mulheres na área de TI?"; (iii) "Quais os resultados obtidos a partir da execução da ação?"; (iv) "Por quem a ação foi promovida e realizada?"; (v) "Quais os recursos necessários para a execução da ação?”.

Para o levantamento das publicações do WIT foi utilizado o repositório do Programa Meninas Digitais (Maciel \& Bim, 2016). Para a seleção das publicações, foram definidos os critérios de inclusão: (CI1) o artigo descrever a execução de ações para a promoção da participação de mulheres na área de TI; (CI2) o artigo descreve resultados da execução de ações para a promoção da participação de mulheres na área de TI. Como critério de exclusão, temos: (CE1) o artigo não atender a nenhum critério de inclusão. A Figura 2 apresenta as etapas executadas do mapeamento sistemático.

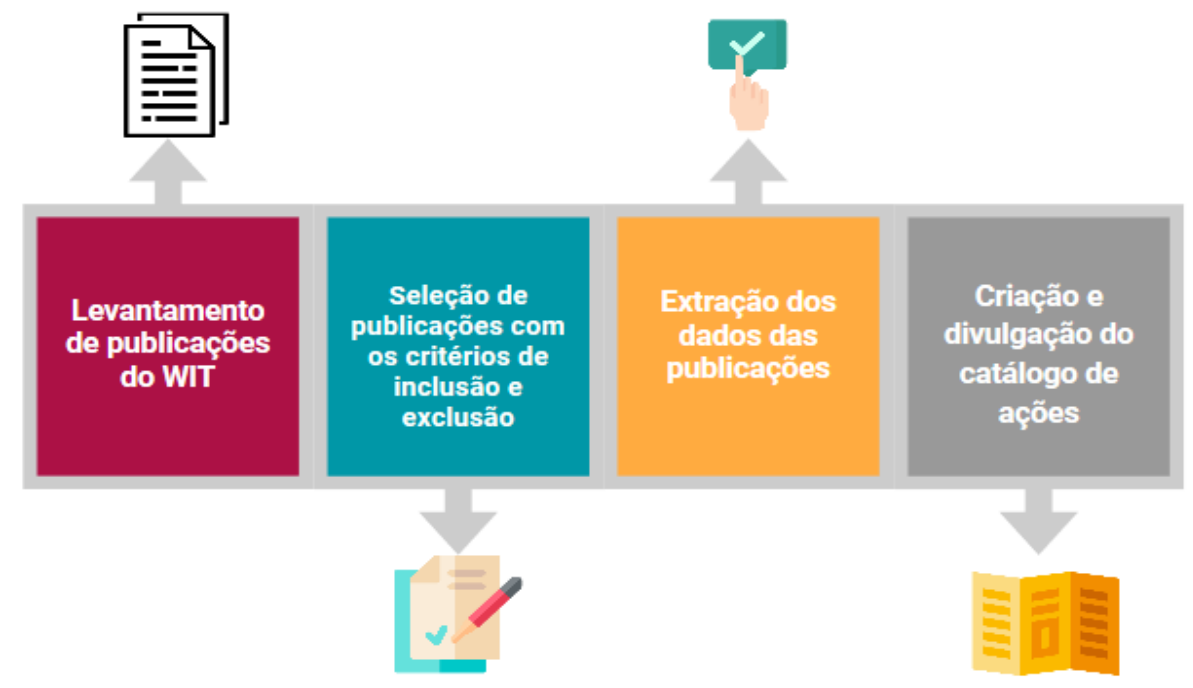

Figura 2. Etapas do mapeamento sistemático

Os dados extraídos das publicações selecionadas foram: nome da ação, objetivo, público alvo, ambiente onde foi realizado, recursos utilizados, promotores e executores da ação, resultados obtidos, publicação na qual está descrita (título do artigo, autores e filiação, ano de publicação). Como resultado da extração realizada a partir dos artigos, foram encontrados um total de 33 ações, distribuídas em sete categorias, como mostra a Figura 3.

$\mathrm{Na}$ categoria oficinas foram identificadas ações de desenvolvimento de aplicativos móveis, desenvolvimento de páginas utilizando HTML, prototipação, técnica de coaching para inspirar as integrantes, entre outras. Segundo Souza et al. (2017), além de inspirar as meninas, outro objetivo da técnica de coaching foi mostrar qualidades que todas as mulheres têm, como: força, garra, inteligência e controle emocional. Ribeiro et al. (2016) apontam que as oficinas promovem uma experiência sobre "como funciona" e "como se faz" que pode motivar as alunas a conhecerem e estudarem mais sobre a área. 


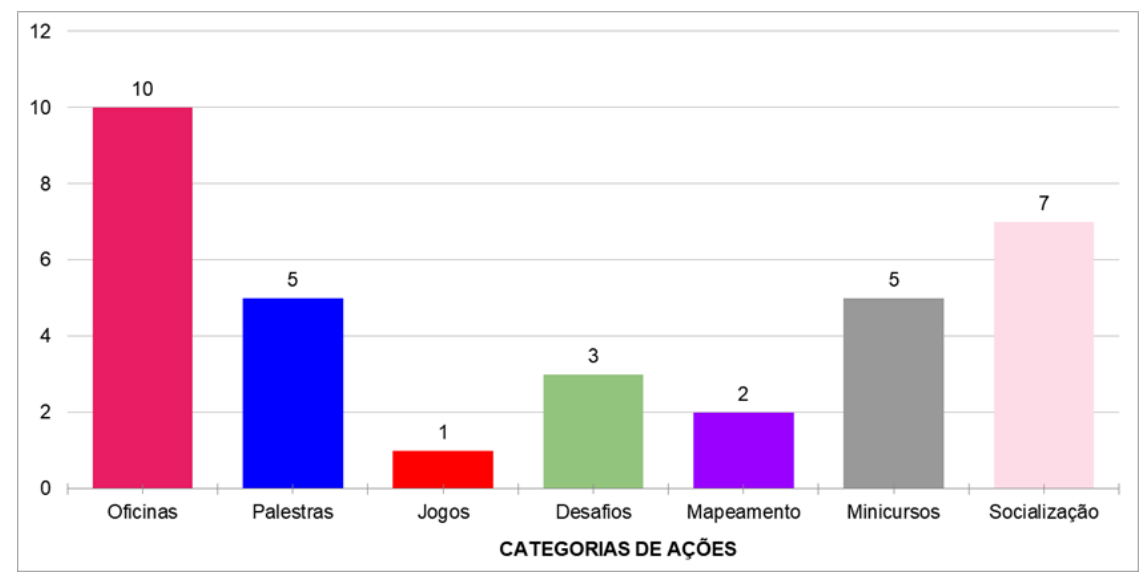

Figura 3. Quantidade de ações encontradas por categoria'.

A categoria palestras envolve ações sobre estímulo à participação feminina em áreas de ciência e tecnologia, debates, fóruns e palestras sobre eletrônica com Arduino. Lauschner et al. (2016) conduziram um fórum direcionado a educadores com o objetivo de discutir e planejar ações a serem realizadas nas escolas do ensino fundamental e médio, bem como nos cursos universitários. A categoria jogos teve apenas uma ação que foi a proposta de um jogo de cartas para ensino de História da Computação (Figueiredo e Santos, 2016) como estratégia para a atração de mais mulheres para a Computação".

A categoria desafios tem ações voltadas para o desenvolvimento de aplicativos, competições e a utilização da técnica Dojo de programação. A categoria minicursos reúne ações sobre robótica e desenvolvimento de jogos em Android. Também foi definido mapeamento como categoria, que por meio da ação de mapear, os autores obtiveram um panorama das iniciativas brasileiras e estrangeiras que fomentam a entrada de mulheres da área da Computação. Por fim, na categoria socialização, existem ações com o objetivo de reunir mulheres para realizar debates, troca de experiências e criação de grupos para reafirmar preconceitos para a partir da discussão desconstruir conceitos estabelecidos (Santos et al., 2017).

Após a extração de dados, o catálogo de ações foi elaborado em formato digital em planilha ${ }^{1}$. Pretende-se divulgar o catálogo em meio digital na página do projeto de pesquisa que está em fase de desenvolvimento. Assim, o catálogo poderá ser consultado por pessoas interessadas em executar ações relacionadas a esta temática.

\subsection{Survey com alunas dos cursos de Engenharia de Software e Ciência da Computação}

Um survey é um método adequado para responder questões do tipo "o que está acontecendo" ou "como e por que algo acontece" (Wohlin et al., 2012). O survey foi realizado por meio da técnica de questionários como metodologia para traçar os perfis das alunas dos cursos de Engenharia de Software e Ciência da computação do campus da UFC em Russas.

Os questionários foram aplicados presencialmente em todas as turmas de Engenharia de Software e Ciência da Computação para alcançar um número significativo de respondentes. Com isso, foi possível alcançar 89 alunas de 104 que eram ativas no

\footnotetext{
${ }^{1} \mathrm{O}$ catálogo completo das ações pode ser consultado em: http://bit.ly/catalogo-acoes-WIT.
} 
período da pesquisa e com os resultados coletados foi possível identificar fatores de desistência e necessidades das alunas em relação aos seus respectivos cursos.

Os questionários eram compostos por 13 questões, sendo duas questões subjetivas e 11 questões objetivas, além da seção de sugestões em relação às ações do projeto. As questões objetivas buscavam identificar o perfil demográfico das alunas (nome, idade, estado civil e renda familiar), os fatores que influenciaram a escolha do curso, as suas experiências universitárias, a área em que pretendem atuar, se já sofreram ou presenciaram algum tipo de preconceito, se o fato de serem mulheres já influenciou a sua vida acadêmica e os fatores que podem influenciar na desistência do curso. As questões subjetivas investigavam a percepção das alunas sobre os seus talentos e pontos que gostariam de melhorar. A Figura 4 apresenta um resumo dos resultados obtidos.

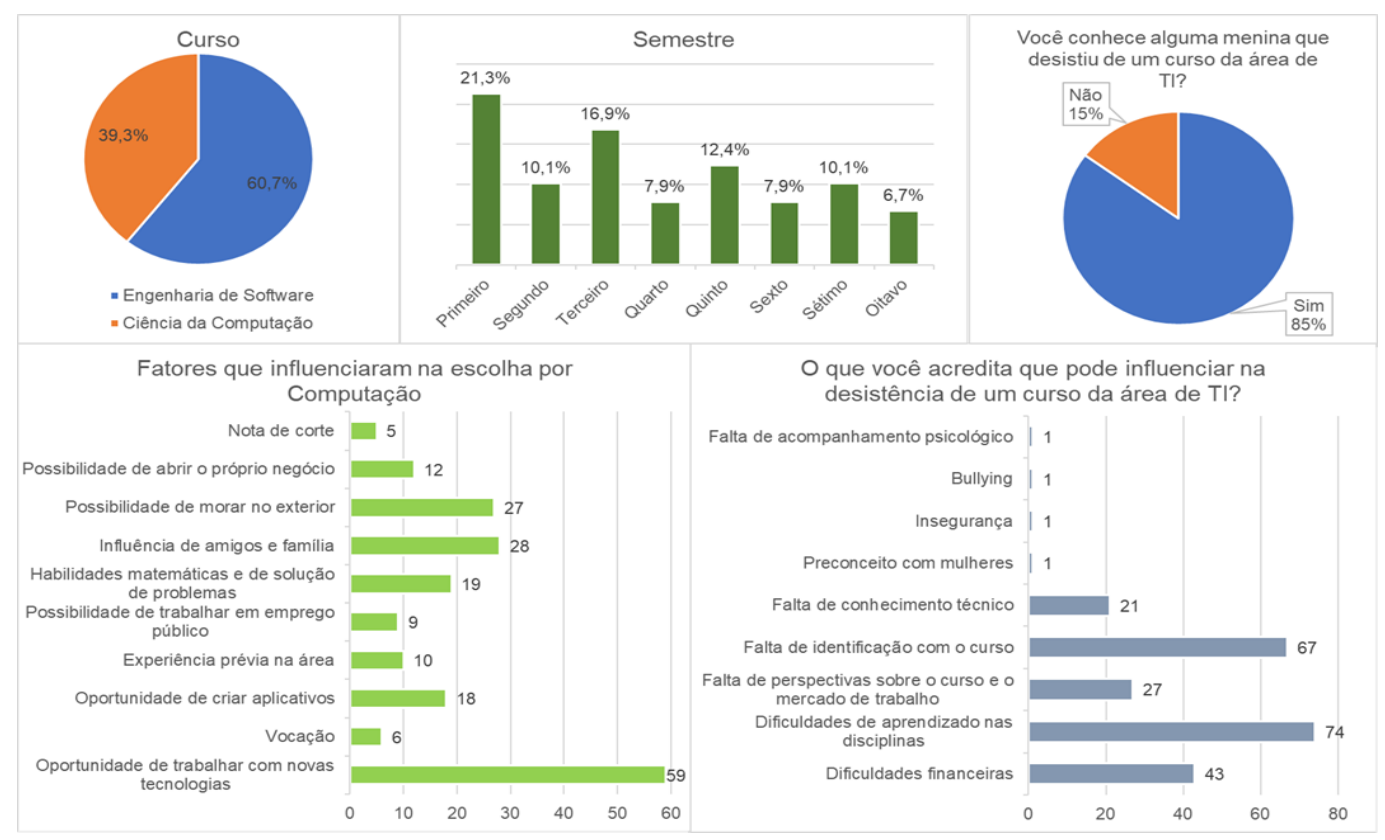

Figura 4. Visão geral dos resultados do survey.

Observa-se que $60,7 \%$ das alunas que responderam ao questionário cursam Engenharia de Software e 39,3\% cursam Ciência da Computação. Houveram respondentes de todos os semestres dos cursos. Notou-se que $85 \%$ das alunas conhecem alguma menina que desistiu do curso. Em relação a quais os fatores que influenciaram na escolha por Computação, a maioria (representada por 59 alunas) indicaram a oportunidade de trabalhar com novas tecnologias. A influência de amigos e familia foi indicada por 28 alunas e a possibilidade de morar no exterior foi mencionada por 27 alunas. A nota de corte foi indicada por 5 alunas e a experiência prévia na área por 10 alunas. Para esta questão, as alunas poderiam marcar mais de uma opção. Outro questionamento investigou o que a aluna acredita que pode influenciar na desistência de um curso de TI. É possível destacar que dificuldades de aprendizado nas disciplinas foi indicado por 74 alunas, a falta de identificação com o curso foi indicada por $67 \mathrm{e}$ dificuldades financeiras foi assinalado por 43 alunas. Os questionários foram analisados para a criação de personas, que são descritas em (Alves et al. 2018).

\subsection{Brainstorming sobre ações adequadas às necessidades $\mathrm{e}$ interesses das alunas}

Durante o planejamento do brainstorming, foram criados cartões contendo: (i) as ações identificadas no mapeamento sistemático; (ii) os fatores de desistência identificados no 
survey; (iii) sugestões de ações fornecidas no survey; (iv) pontos que as alunas respondentes do survey desejam melhorar em seu desenvolvimento acadêmico e profissional. A equipe analisou de que forma as ações identificadas no mapeamento sistemático poderiam auxiliar no desenvolvimento dos pontos a melhorar e reduzir os fatores de desistência. As sugestões de ações foram utilizadas como base para selecionar ações adequadas. A equipe organizou os cartões em quatro grupos (Figura 5).

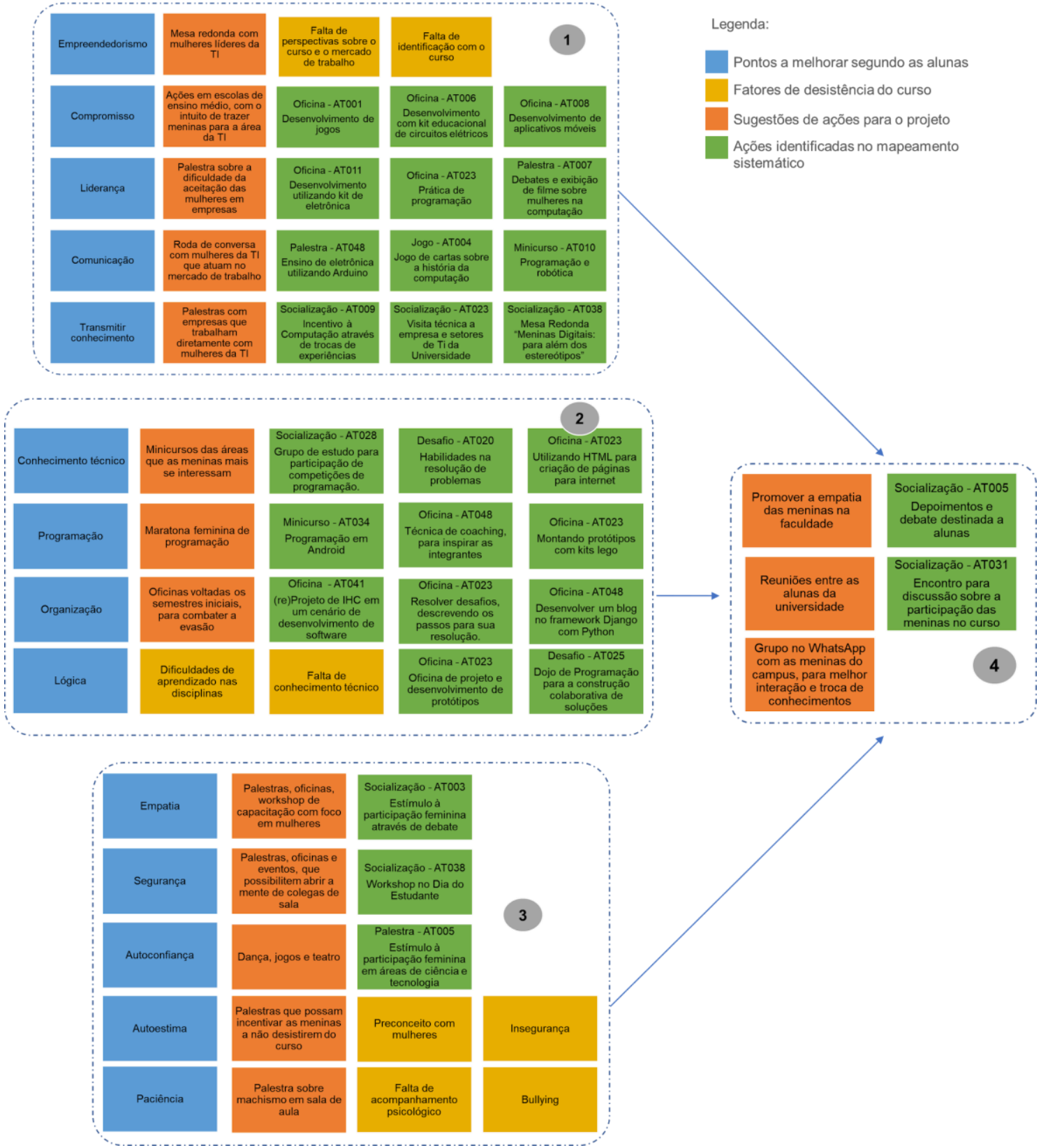

Figura 5. Mapa mental elaborado no brainstorming.

Não foram identificadas ações que reduzissem diretamente o fator de desistência dificuldades financeiras. Porém, a equipe concluiu que o Grupo 1, que trata da falta de perspectivas sobre o mercado de trabalho e o Grupo 2, que aborda a falta de conhecimento técnico, poderiam apoiar as alunas a desenvolverem competências e habilidades da área e, consequentemente, conquistarem oportunidades de bolsas na universidade ou estágios na indústria. 


\section{Execução de ações direcionadas ao campus e à comunidade}

A partir dos resultados obtidos no brainstorming, foi realizado um planejamento de ações para o ano de 2018. Nesta seção, as ações realizadas no âmbito do projeto serão resumidamente descritas.

Realização de palestras sobre a contribuição de mulheres para a área de Computação: o projeto promoveu três palestras sobre os temas: (1) "Por que discutir a participação feminina na área de Tecnologia?" foi realizada durante o evento FLISoL 2018 com foco na instalação de software livre e com a participação de estudantes e profissionais de outras instituições; (2) "Computação e Gênero: promovendo a diversidade" foi uma palestra convidada pela coordenação dos cursos de Ciência da Computação e Engenharia de Software; e (3) "A importância da formação de mulheres para a área de Tecnologia" foi realizada no Dia do Estudante.

Experiências com jogos educacionais para o ensino de Computação: foram realizadas experiências com o jogo não-digital Computasseia para o ensino de História da Computação (Figueiredo \& Santos, 2016) em dois cursos de extensão ofertados no campus e no evento Ada Lovelace Day, realizado para os estudantes do campus. Também foi realizado o evento "Hora do Código", no qual os estudantes de ensino médio de uma escola pública do município de Russas experimentaram um jogo digital da plataforma Code.Org, uma plataforma para ensino de lógica de programação.

Caravana para eventos de tecnologia direcionados à mulheres: para incentivar a participação das alunas do campus em eventos de tecnologia, o projeto organizou duas caravanas para dois eventos realizados em Fortaleza (CE). No evento ByteGirl, participaram 25 alunas e duas professoras como ouvintes. No evento International Women's Day promovido pela comunidade WomenTechmakers Fortaleza, além de 12 alunas ouvintes, duas alunas conduziram uma oficina de Design Thinking e a coordenadora do projeto participou como palestrante. Este resultado indica que o projeto está expandindo sua participação na comunidade de mulheres na área de TI.

Oficinas de Design Thinking para criação de aplicações inovadoras: o Design Thinking é uma abordagem centrada no usuário para fomentar a inovação, considerando métodos como observação, colaboração, aprendizado, prototipação de ideias e testes (Brown, 2008). Foram conduzidas duas oficinas de Design Thinking no âmbito deste projeto. A primeira oficina foi conduzida durante uma semana temática dos cursos de Engenharia de Software e Ciência da Computação, aberta ao público externo. Esta oficina teve a participação de 25 estudantes de ensino médio e graduação. A segunda oficina foi ofertada em um evento de tecnologia direcionado à mulheres e realizado em comemoração ao Dia Internacional da Mulher. Nesta oficina, participaram 30 mulheres da área de TI entre estudantes e profissionais da indústria.

Fóruns para troca de experiências acadêmicas e profissionais: foram promovidos dois fóruns em dois diferentes eventos realizados no campus para promover um debate sobre a carreira acadêmica e profissional na área da Computação a partir do relato de experiência das docentes dos cursos de Ciência da Computação e Engenharia de Software, de alunas egressas do curso e de profissionais da indústria da região.

Publicação de cartazes sobre mulheres da Computação: com o intuito de divulgar informações sobre mulheres com destaque na área da Computação no âmbito nacional e internacional, foi realizado um levantamento de informações e foram 
elaborados (inicialmente) cartazes sobre as seguintes mulheres: Susan Wojcicki, Camila Achutti, Ada Lovelace e Thais Batista. A cada mês, um cartaz diferente foi fixado em diferentes pontos do campus (cantina, restaurante universitário e centros acadêmicos).

Divulgação das ações e resultados do projeto para a comunidade acadêmica e para a sociedade: como meio de comunicação com a comunidade, foi criado um perfil do projeto no instagram @meninasdigitaisdovale, onde são publicadas e divulgadas todas as ações a serem realizadas, bem como os registros das ações promovidas no âmbito do projeto. Outra estratégia para divulgação dos resultados obtidos é a escrita de artigos científicos pelas alunas do projeto. A universidade promove anualmente o evento Encontros Universitários (EU), no qual os estudantes submetem resumos sobre os resultados de pesquisas científicas, pesquisas de extensão e monitorias. Em 2018, três resumos foram apresentados por alunas do projeto, relatando experiências vivenciadas no projeto, sendo um dos resumos reconhecido com menção honrosa. Ademais, duas alunas do projeto apresentaram um artigo (Alves et al. 2018) no IHC 2018 (Simpósio Brasileiro sobre Fatores Humanos em Sistemas Computacionais), evento referência na área de IHC.

\section{Lições Aprendidas e Considerações Finais}

O projeto Meninas Digitais do Vale possibilitou o desenvolvimento de atividades de pesquisa, ensino e extensão. As alunas da equipe tiveram contato com pesquisas científicas nas áreas de IHC e Engenharia de Software, obtendo experiências para o desenvolvimento de futuras pesquisas, inclusive Trabalhos de Conclusão de Curso. A preparação de materiais didáticos e condução de oficinas forneceu experiências de ensinoaprendizagem. O networking em eventos realizados nas escolas do município e em eventos de tecnologias em outras cidades, possibilitou uma maior integração das alunas do projeto e do campus com a comunidade de mulheres na TI, ultrapassando as fronteiras da universidade.

Como aspecto facilitador do projeto, observou-se que a temática do projeto despertou o interesse de várias alunas para atuarem como voluntárias no projeto. Em 2019, foi possível obter duas bolsas por meio de editais lançados pela universidade. Espera-se, assim, tornar a participação das alunas mais efetiva. Como lições aprendidas, é possível destacar: (i) devido à ausência de apoio financeiro no primeiro ano do projeto, a equipe comercializa produtos do projeto como camisas e copos para que o lucro seja utilizado para suprir a demanda de confecção de material de apoio para oficinas e outras atividades; (ii) a divulgação de ações do projeto é realizada por meio de redes sociais, o que reduz a necessidade de impressão de cartazes e permite um maior alcance das informações; (iii) para formar uma comunidade de alunas do campus foi criado um grupo no aplicativo Whatsapp que permite a troca de informações sobre os eventos do projeto e organização de caravanas de alunas para participação em eventos externos.

Neste primeiro ano de execução do projeto, foi possível obter: (i) um levantamento sobre o perfil das alunas dos cursos de Computação do campus; (ii) divulgação sobre a participação de mulheres na área de Computação no campus e na sociedade; (iii) realização de oficinas de prototipação e experiências com jogos sobre História da Computação e Lógica de Programação para alunos de graduação e alunos de ensino médio; (iv) publicação de trabalhos científicos para disseminação dos resultados do projeto para a comunidade acadêmica. 
Como próximos passos, pretende-se elaborar um cronograma de visitas nas escolas da região para divulgar o projeto e obter um maior alcance às alunas de ensino médio e fundamental; ofertar no campus cursos de extensão com carga horária de 15 a 20 horas para o desenvolvimento de aplicativos com AppInventor e projeto de aplicativos com Design Thinking; realizar rodas de conversa entre as alunas do campus para promover uma maior integração, sororidade e empoderamento; investigar os fatores que levam à evasão, por meio de contato direto com alunas que desistiram do curso.

\section{Referências}

Alves R.O., Castelo Branco, K., \& Marques, A.B. (2018). "Criação de personas para delinear o perfil de alunas de cursos de graduação de TI e direcionar ações para o fortalecimento e empoderamento feminino". In Anais Estendidos do XVII Simpósio Brasileiro sobre Fatores Humanos em Sistemas Computacionais.

Brown, Tim. "Design thinking." Harvard business review 86.6 (2008): 84.

Cesário, G., Silveira, N.G., Bim, S.A., Maciel, C. (2017) "Por Mais Mulheres na Computação: análise dos trabalhos publicados no $\mathrm{X}$ Women in Information Technology". $11^{\circ}$ WIT-Women in Information Technology.

Figueiredo, K. S.; Santos, J. C. O. (2016) “Computasseia: Destacando a Participação Feminina na História da Computação," $10^{\circ}$ Women in Information Technology (WIT 2016).

Lauschner, T., Freitas, R., Nakamura, F., \& de Gomes, L.L.A. (2016). "Cunhantã digital: programa de incentivo a participação de mulheres da região amazônica na computação e áreas afins". In 10o Women in Information Technology (WIT 2016), Porto Alegre, RJ, In: Anais do XXXVI Congresso da Sociedade Brasileira de Computação (CSBC 2016)

Maciel, C., Bim, S. A. (2016) "Programa Meninas Digitais ações para divulgar a Computação para meninas do ensino médio". In: Computer on the Beach, 2016, Florianópolis. Anais [do] Computer on the Beach, p. 327-336.

Ribeiro, H., de Carli, I.C.S, Lima, M.F.W.P, Paiva, S.C.M, Luciano, N.A. (2016) "Trazendo Meninas para a Computação". In: XXXVI CSBC (Congresso da Sociedade Brasileira de Computação), 2016, Porto Alegre.

Santos, J., Ferreira, A., Oliveira, A., Santos, D., \& Matos, E. (2017). Meninas Digitais Regional Bahia: os primeiros bits. In $11^{\circ}$ Women in Information Technology (WIT 2017). Porto Alegre: SBC.

Souza, A. C., Perkoski, I., Veiga, K., \& Romankiv, V. (2017). Relato Tech Ladies: redes de colaboração entre mulheres na tecnologia. In $11^{\circ}$ Women in Information Technology (WIT 2017) (Vol. 11, No. 1/2017). SBC.

SBC (2017) "Educação Superior em Computação Estatísticas". Disponível em: < http://www.sbc.org.br/documentos-da-sbc/summary/133-estatisticas/1200-pdf-pngeducacao-superior-em-computacao-estatisticas-2017>. Acesso em: 14/12/2018.

Wohlin, C., Runeson, P., Höst, M., Ohlsson, M. C., Regnell, B., \& Wesslén, A. (2012). Experimentation in software engineering. Springer Science \& Business Media. 